\section{Ultrasonographic imaging of papillary thyroid carcinoma variants}

\author{
Jung Hee Shin \\ Department of Radiology and Center for Imaging Science, Samsung Medical Center, \\ Sungkyunkwan University School of Medicine, Seoul, Korea
}

Ultrasonography (US) is routinely used to evaluate thyroid nodules. The US features of papillary thyroid carcinoma (PTC), the most common thyroid malignancy, include hypoechogenicity, spiculated/microlobulated margins, microcalcifications, and a nonparallel orientation. However, many PTC variants have been identified, some of which differ from the classic type of PTC in terms of biological behavior and clinical outcomes. This review describes the US features and clinical implications of the variants of PTC. With the introduction of active surveillance replacing immediate biopsy or surgical treatment of indolent, small PTCS, an understanding of the US characteristics of PTC variants will facilitate the individualized management of patients with PTC.

Keywords: Ultrasonography; Thyroid cancer, papillary; Papillary thyroid carcinoma variant; Thyroid neoplasms

\section{Introduction}

Papillary thyroid carcinoma (PTC) has an excellent prognosis, with an overall cancer-related 10year survival rate of nearly $90 \%[1,2]$. Many variants of PTC have been documented [3]. With the existence of nuclear features, each variant has a combination of specific growth patterns, cell types, and stromal changes. Some variants are more aggressive, whereas others are more indolent, which contributes to risk stratification. Recently, the revised American Thyroid Association guidelines classified PTC variants according to their biological behavior as described in the literature [4] (Table 1). The histopathological variants of PTC associated with more unfavorable outcomes are the tall cell variant (TCV), the columnar cell variant, and the hobnail variant. Although the data remain controversial, the solid variant and the diffuse sclerosing variant (DSV) may be associated with less favorable outcomes. In contrast, the encapsulated follicular variant (FV), the cribriform-morular variant (CMV) (which is related to familial tumor syndromes), and the recently described Warthin-like variant (WV) are associated with favorable outcomes. However, the guidelines contain no information about the imaging characteristics of the variants of PTC.

Via high-resolution ultrasonography (US), thyroid nodules can be detected and, additionally, some malignant histological types can be specifically diagnosed [4-7]. Since US is the primary means of assessing thyroid nodules and provides a basis for surgical decisions, the US imaging features of the variants of PTC and their clinical implications will be described herein.

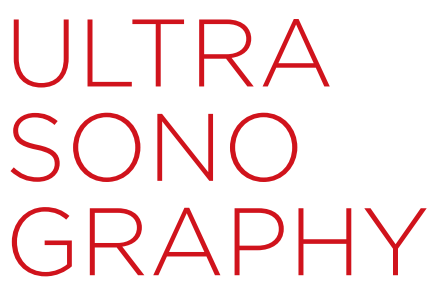

\section{REVIEW ARTICLE}

https://doi.org/10.14366/usg. 16048 pISSN: 2288-5919 • elSSN: 2288-5943

Ultrasonography 2017;36:103-110

Received: December 14, 2016

Revised: January 11, 2017

Accepted: January 12, 2017

Correspondence to:

Jung Hee Shin, MD, PhD, Department of Radiology and Center for Imaging Science, Samsung Medical Center,

Sungkyunkwan University School of Medicine, 81 Irwon-ro, Gangnam-gu, Seoul 06351, Korea

Tel. +82-2-3410-2548

Fax. +82-2-3410-0049

E-mail: jhshin11@skku.edu
This is an Open Access article distributed under the terms of the Creative Commons Attribution NonCommercial License (http://creativecommons.org/ licenses/by-nc/3.0/) which permits unrestricted noncommercial use, distribution, and reproduction in any medium, provided the original work is properly cited.

Copyright (C) 2017 Korean Society of Ultrasound in Medicine (KSUM)

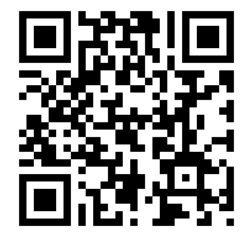

How to cite this article:

Shin JH. Ultrasonographic imaging of papillary thyroid carcinoma variants. Ultrasonography. 2017 Apr;36(2):103-110. 
Table 1. Classification of papillary thyroid carcinoma variants according to biological behavior in the 2015 American Thyroid Association guidelines

\begin{tabular}{|c|c|c|}
\hline Aggressive & Less favorable & Favorable \\
\hline Tall cell variant & Solid variant & $\begin{array}{l}\text { Follicular (encapsulated) } \\
\text { variant }\end{array}$ \\
\hline $\begin{array}{l}\text { Columnar cell } \\
\text { variant }\end{array}$ & Diffuse sclerosing variant & $\begin{array}{l}\text { Cribriform-morular } \\
\text { variant }\end{array}$ \\
\hline Hobnail variant & & Warthin-like variant \\
\hline
\end{tabular}

\section{Aggressive Variants}

\section{Tall Cell Variant}

The TCV is composed of more than $50 \%$ tall cells, which are twice or three times as tall as wide and have eosinophilic cytoplasm and characteristic PTC nuclear features [8]. Some pathologists recommend noting the percentage of tall cells in the pathology report when it is significant $(\geq 30 \%)$, irrespective of the cutoff used to designate a tumor as a TCV. The incidence of TCV has been reported to range from $4 \%$ to $17 \%$ of PTCs [9]. The TCV can be missed by pathologists not only because of its rarity but also due to its blurred definition. The TCV seems to be more aggressive even when it lacks extrathyroidal extension. TCV without extrathyroidal extension has been found to show higher rates of recurrence and distant metastasis than classic PTC without extrathyroidal extension ( $14.9 \%$ vs. $6.5 \%$ and $6.4 \%$ vs. $0 \%$, respectively) [9]. The poorer prognosis of the TCV reflects the older age of patients at presentation, the larger size of the tumor, and a higher frequency of extrathyroidal extension [10]. The BRAF V600E mutation is found in up to $92.6 \%$ of TCV tumors [11].

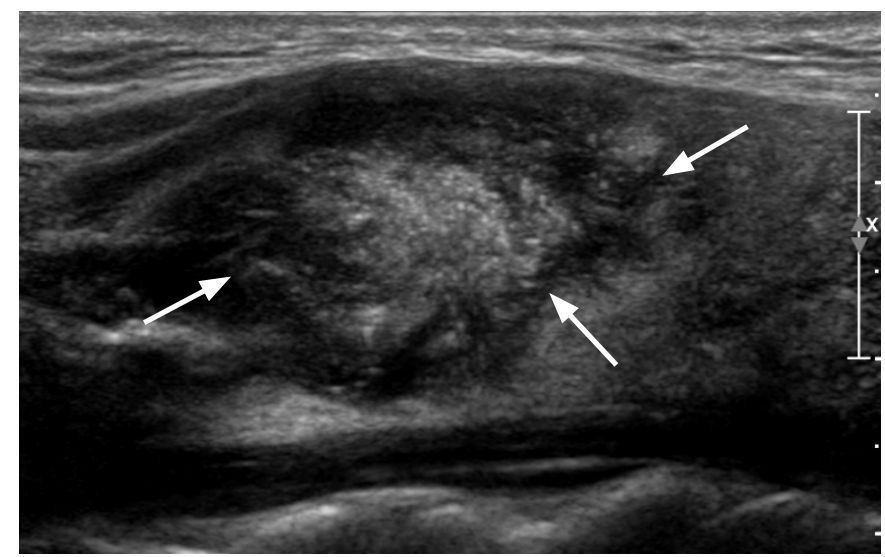

A
On ultrasonography, TCV tumors often appear as microlobulated, markedly hypoechoic nodules with microcalcifications and extrathyroidal extension, and are always associated with lymph node metastasis (Fig. 1). TCV PTC should be included in the differential diagnosis of aggressive thyroid tumors because it almost always appears as a highly suspicious nodule on US [12].

\section{Columnar Cell Variant}

In earlier publications, the columnar cell variant was thought to always be aggressive; however, the encapsulated form is now associated with a favorable outcome after complete excision. The poor prognosis and aggressive behavior of the columnar cell variant warrant its early recognition.

The columnar cell variant is lined by elongated hyperchromatic pseudostratified columnar cells. It is very rare, with only approximately 50 cases reported since its first description in 1986 by Evans [13]. Its prognosis is variable: more favorable when the tumor is small, encapsulated, and circumscribed, and less favorable when the tumor is large and metastatic with extrathyroidal extension [14]. The BRAF V600E mutation is found in one-third of these tumors [15].

Little information has been published about the imaging features of columnar cell variants. On US, encapsulated tumors appear as circumscribed hypoechoic nodules with or without microcalcifications (Fig. 2), and aggressive tumors as large microlobulated hypoechoic nodules, often with capsular protrusions representing extrathyroidal extension and neck nodal metastasis.

\section{Hobnail Variant}

The hobnail variant has apically placed nuclei and a surface bulge in $>30 \%$ of its cells [16]. This rare variant is more closely associated

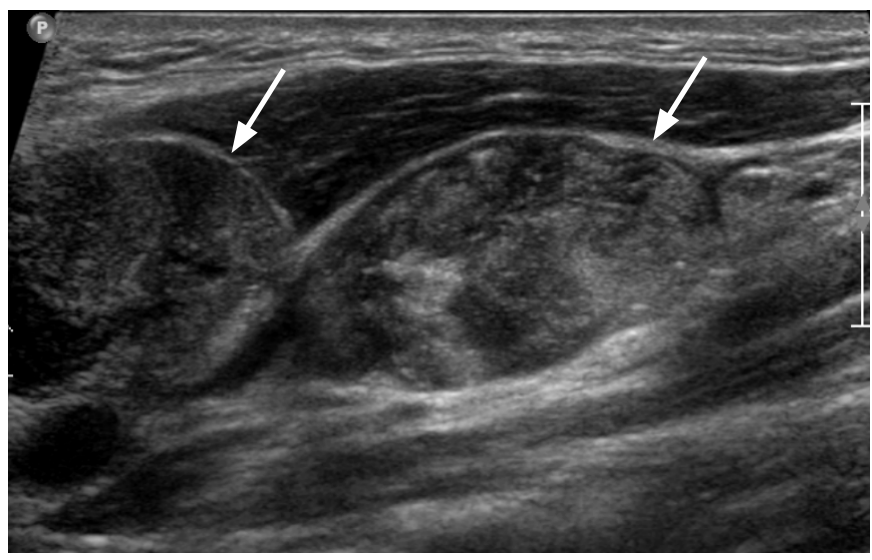

B

Fig. 1. Tall cell variant of papillary thyroid carcinoma in a 19-year-old female woman.

A. Longitudinal ultrasonography shows a microlobulated hypoechoic nodule (arrows) with microcalcifications and extrathyroidal extension in the right thyroid gland. B. Metastatic lymph nodes (arrows) are coexistent in the lateral neck. 


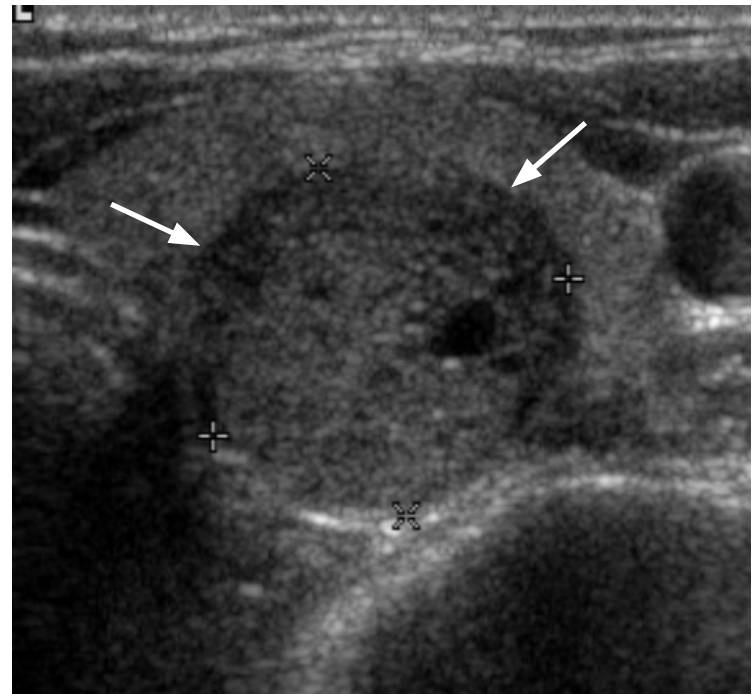

A

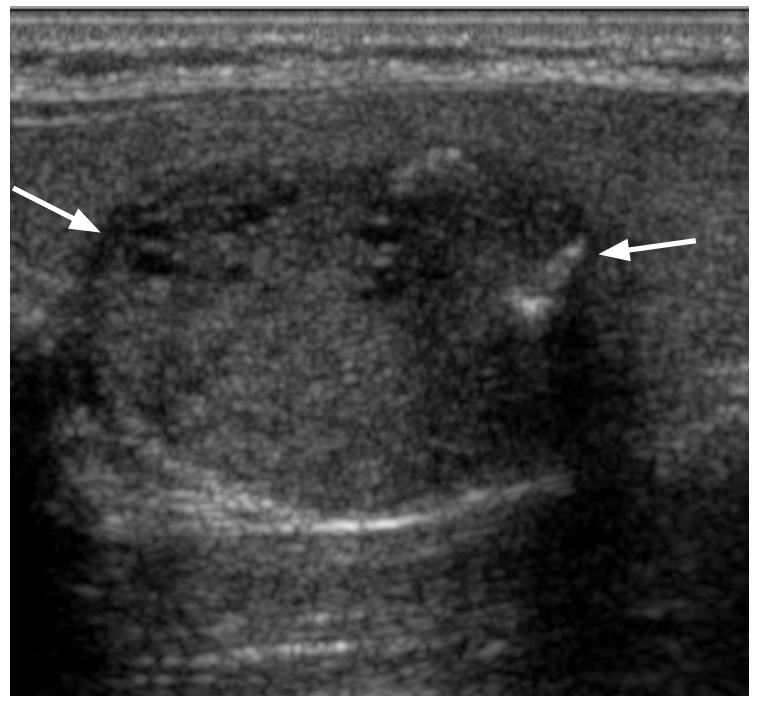

B

Fig. 2. Columnar cell variant of papillary thyroid carcinoma in a 27-year-old woman.

A, B. Transverse (A) and longitudinal (B) ultrasonography shows a circumscribed hypoechoic nodule (arrows) with calcifications and cystic changes in the left thyroid gland, suggesting an encapsulated tumor.

with recurrence, metastasis, and cancer-related death than is classic PTC [17].

In a previous report, eight of 10 hobnail variant cases had the BRAF V600E mutation, whereas none had an ALK fusion or TERT promoter mutation. In a literature review of 55 hobnail variant cases, most patients presented with advanced-stage cancer, and the disease-specific survival rates were $83 \%, 71 \%$, and $54 \%$ at 5,10 , and 20 years after the initial operation, respectively [18].

The imaging features of the hobnail variant have not been reported owing to its rarity. This variant has been found to show a palpable mass appearing as a microlobulated hypoechoic nodule with microcalcifications and multiple metastatic lymph nodes on US.

\section{Less Favorable Variants}

\section{Solid Variant}

The solid variant comprises approximately $3 \%$ of all PTCs [19], and there are conflicting reports about its behavior in the literature. It has been identified in more than $30 \%$ of the survivors of the Chernobyl nuclear accident $[20,21]$. Compared with welldifferentiated tumors, the solid variant appears to have a slightly greater rate of distant metastasis, a less favorable prognosis, and a less favorable survival rate. Among children and adolescents with post-Chernobyl PTCs, the percentage of solid variants was very low $(<1 \%)$ during the first 10 years of follow-up [21]. In a recently published report, none of the patients with solid-variant PTCs had a history of radiation exposure [22]. The authors concluded that the clinical characteristics of the solid variant, including the frequency of lymph node metastasis, distant metastasis, and recurrence, did not differ from those of classic PTC, presumably due to the small size of the tumors (all tumors in their series were $<2.0 \mathrm{~cm}$ ) and the early detection of the thyroid cancer. Early detection of small PTCs via imaging and preoperative fine-needle aspiration appears to be important.

Histologically, more than $50 \%$ of solid variants have a solid growth pattern, with nests of non-necrotic tumor cells surrounded by a thin rim of capillary-rich connective tissue and the intact nuclear features of classic PTCs [19]. The solid variant should be distinguished from poorly differentiated thyroid carcinomas, which have similar insular, solid, and trabecular growth patterns and a lower survival rate [20].

These tumors have been diagnosed as high- or intermediatesuspicion nodules using US based on the Korean Thyroid Image Reporting and Data System $[23,24]$. Some tumors have been reported to have a well-defined border and could be predicted to exhibit indolent behavior [25].

\section{Diffuse Sclerosing Variant}

As described by the World Health Organization, DSV PTC tends to occur in young women and is characterized by the diffuse involvement of one or both thyroid lobes, usually without formation of a dominant mass, and by extensive squamous metaplasia, numerous psammoma bodies, dense lymphocytic infiltration, and stromal fibrosis. 
The DSV was proposed as a new PTC variant by Vickery et al. in 1985 [26] and officially recognized as a histological variant in 1988 [27].

The prognostic implications of the DSV remain controversial. Some studies reported a high incidence of lymph node metastasis and lung metastasis at presentation, thus suggesting that the DSV has a less favorable prognosis than does classic PTC [28-30]. Other reports, however, found no differences [31,32].

A recent meta-analysis confirmed the aggressive biological behavior of the DSV. When preoperatively suspected, DSV PTC should be treated via total thyroidectomy with lymph node excision followed by radioiodine therapy [33]. In a large multicenter study, the DSV had a 7-year recurrence-free survival rate of $63 \%$, which is significantly worse than that of other PTC variants. Despite aggressive surgical interventions, the risk of recurrence of DSV PTC requires constant meticulous surveillance, similar to the follow-up protocol for other high-risk PTC patients, during the first 5 years after treatment [34].

RET/PTC rearrangement is the major genetic alteration in DSV PTC, whereas the prevalence of the BRAF mutation is relatively low (24\%) [35]. The US features of the DSV include a heterogeneous echotexture in the parenchyma, an ill-defined solid hypoechoic nodule when formed as a mass, scattered microcalcifications within or without the nodule (appearing as a "snowstorm"), and representative psammoma bodies on pathology (Fig. 3) [36]. Lateral nodal metastasis with microcalcifications is frequently detected.

It is sometimes difficult to differentiate DSV PTC from chronic thyroiditis manifesting with only microcalcifications. DSV PTC is common in young patients and is always accompanied by cervical metastatic lymph nodes, whereas chronic thyroiditis is common in middle-aged patients and frequently accompanied by benign reactive lymph nodes. Patients with chronic thyroiditis have a history of hypothyroidism.

\section{Favorable Variants}

\section{Follicular Variant}

The FV is the most common type of PTC after classic PTC [37]. It possesses both the nuclear features of PTC (e.g., nuclear clearing, grooves, and pseudoinclusions) and a follicular growth pattern [38]. FV tumors are divided into two main subgroups-infiltrative and encapsulated-that differ in their molecular profiles and biological properties. Infiltrative FV PTCs frequently harbor BRAF mutations and exhibit aggressive behavior, whereas encapsulated FV PTCS have a high frequency of RAS mutations and indolent behavior [39]. Infiltrative FV PTCs do not differ significantly from conventional PTCs in terms of prognostic factors or survival rate.

Some investigators have suggested that US can predict the behavior of the FV because FV PTC has dichotomous US features (PTC-like vs. follicular neoplasm-like). FV tumors with malignant US features seem to behave more aggressively than do FV tumors without malignant US features $[40,41]$.

Recently, encapsulated FV tumors were classified into invasive and noninvasive encapsulated FV PTC [42]. Noninvasive encapsulated

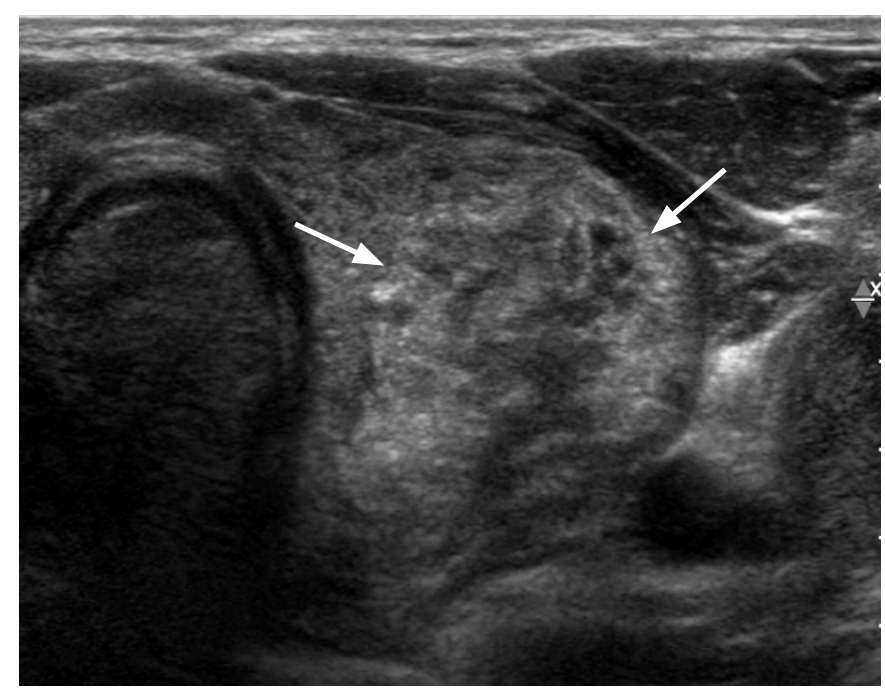

A

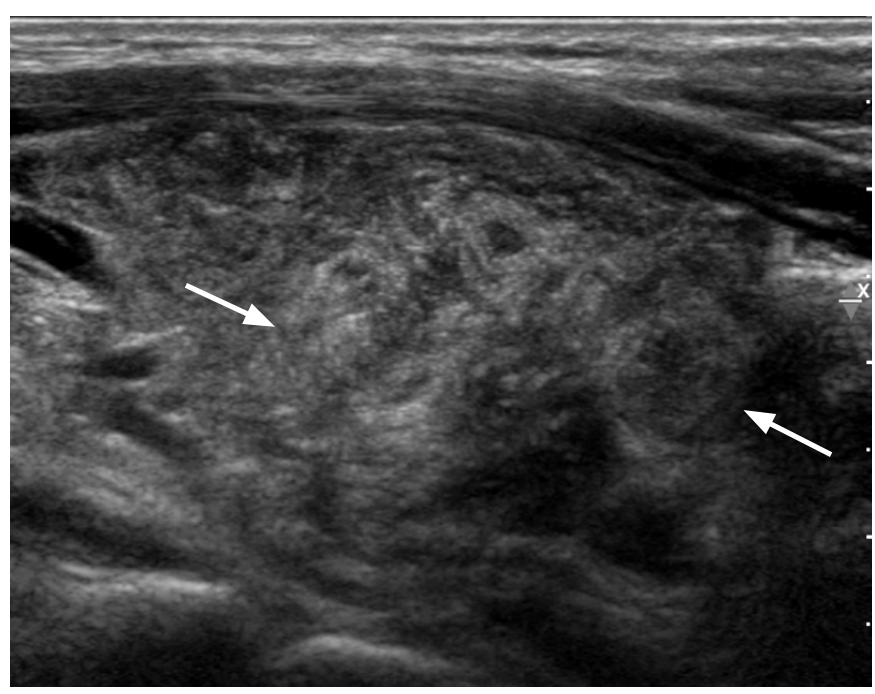

B

Fig. 3. Diffuse sclerosing variant of papillary thyroid carcinoma in a 22-year-old male patient.

A, B. Transverse (A) and longitudinal (B) ultrasonography shows an ill-defined hyperechoic nonmass-like lesion (arrows) with scattered microcalcifications in the left thyroid gland. Metastatic lymph nodes were noted in the left lateral neck (not shown). 
FV tumors have a very low risk of adverse outcomes, whereas invasive encapsulated FV tumors have a $12 \%$ risk of recurrence and a $2 \%$ risk of tumor-related mortality. It has been proposed that the noninvasive encapsulated FV be termed noninvasive follicular thyroid neoplasm with papillary-like nuclear features (NIFTP) [42]. NIFTP occupies an intermediate position between true benign lesions and invasive cancer and can be removed by limited surgery. Surgical removal is necessary to evaluate the extent of tumor invasion and to prevent possible progression to invasive encapsulated FV PTC [43]. Therefore, the pathological evaluation of these tumors should include the microscopic examination of the entire tumor capsule to exclude invasion.

A multicenter study found that NIFTP lacked malignant US features and frequently showed hyperechogenicity or isoechogenicity, a circumscribed margin, and no calcification on US. It recommended the performance of US-guided core needle biopsy rather than USguided fine needle aspiration for better triage and to facilitate surgical management. US evaluation is pivotal in determining the next step of FV PTC management. In a previous study, central nodal metastasis was identified in only one of 34 NIFTP cases (2.9\%), none of which exhibited distant metastasis or recurrence $[44,45]$. Infiltrative FV PTCs are not overlooked when the current system for detecting thyroid nodules based on US features is used. However, differentiating between encapsulated FV tumors and NIFTPs via US is still challenging and requires further research (Fig. 4).

\section{Cribriform-Morular Variant}

The CMV is a rare type of tumor that occurs in patients with autosomal dominant inherited familial adenomatous polyposis
(FAP), although sporadic isolated cases have been reported $[46,47]$. Multiplicity usually is present in patients with FAP [48]. In such patients, CMV PTC may be diagnosed before colonic manifestations are apparent; hence, its proper identification is essential for the prompt assessment of colonic disease and APC gene status, as well as timely familial counseling. CMV PTC has an early age of onset (age range, 19 to 46 years) and female predominance [48]. It is histologically characterized by the papillary growth of tall columnar cells, a cribriform pattern without colloids, and the presence of spindle cells, squamoid morules, and nuclear clearing. $\beta$-Catenin immunostaining is important for the definitive diagnosis of CMV PTC [49].

Previous studies have shown that that most CMV tumors do not exhibit malignant features on US [48]. Rather, their most common US feature is the presence of oval, circumscribed, heterogeneous, and hypoechoic solid nodule(s) without a hypoechoic halo or calcification (Fig. 5). It is not easy to diagnose this type of PTC preoperatively based solely on US features and cytology.

\section{Warthin-like Variant}

First described in 1995, the WV is a rare entity that resembles the Warthin tumor of the salivary gland [50]. It consists of cells with oncocytic cytoplasm and the nuclear features of papillary carcinoma that line the papillary structures with dense lymphocytic infiltration in the stalks. The presence of lymphocytic stroma in a thyroid tumor is thought to indicate a favorable prognosis, with tumor-associated lymphocytes contributing to the control of tumor growth [50]. Associated Hashimoto thyroiditis was observed in $93 \%$ to $100 \%$ of the reported patients with WV PTC [51]. The WV has a significantly

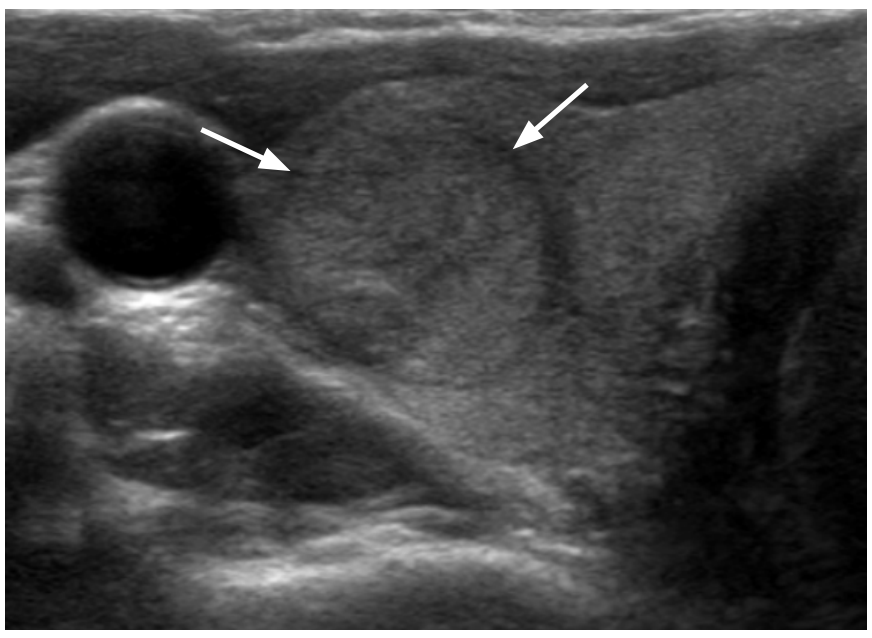

A

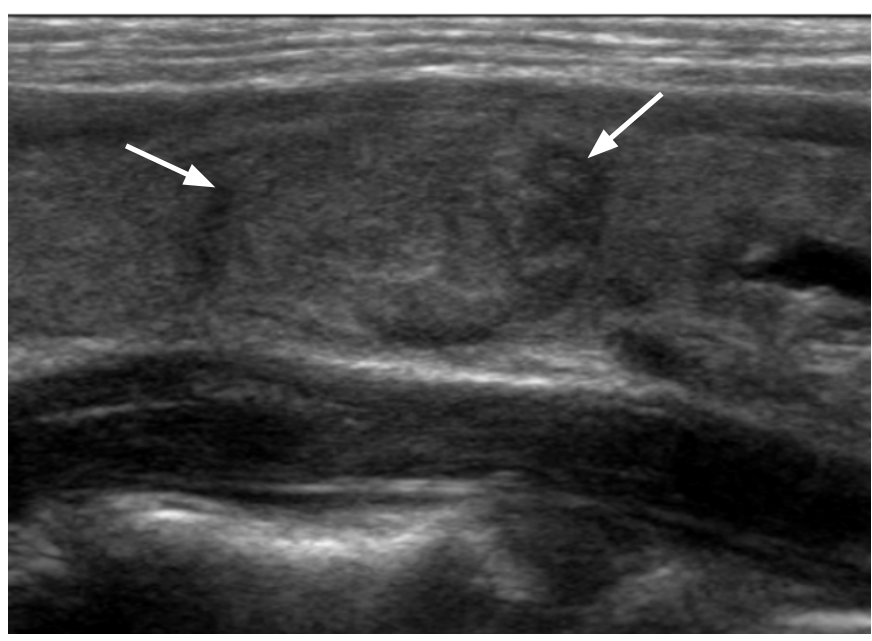

B

Fig. 4. Noninvasive follicular thyroid neoplasm with papillary-like nuclear features (NIFTP) in a 44-year-old man.

A, B. Transverse (A) and longitudinal (B) ultrasonography shows an oval smooth isoechoic nodule (arrows) in the right thyroid gland. 


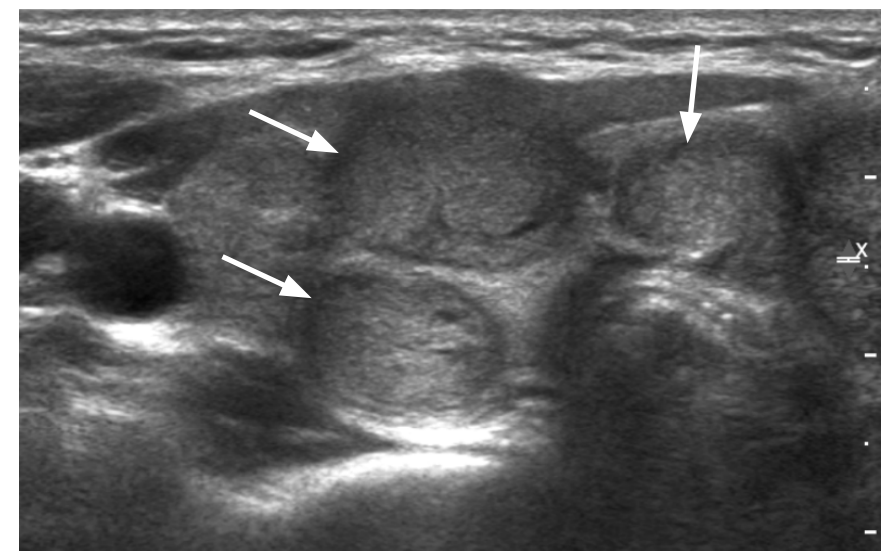

A

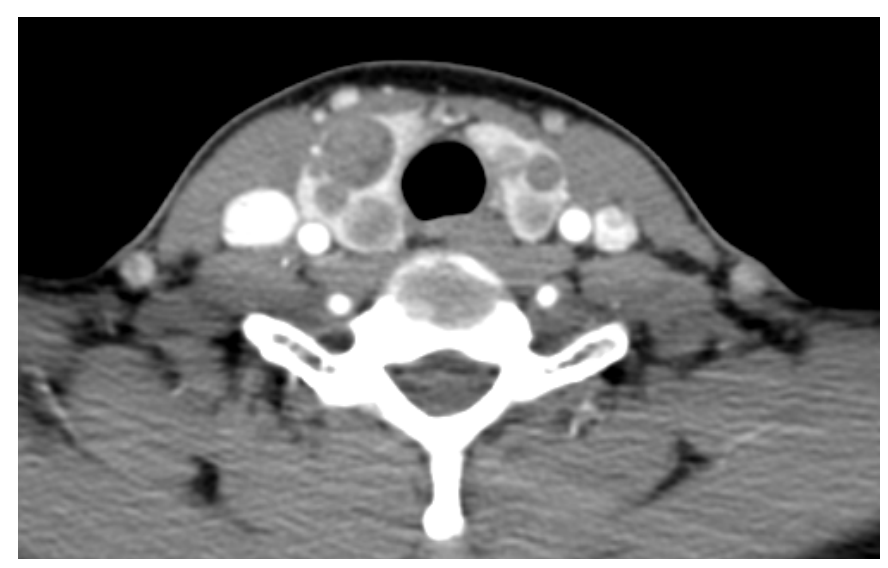

c

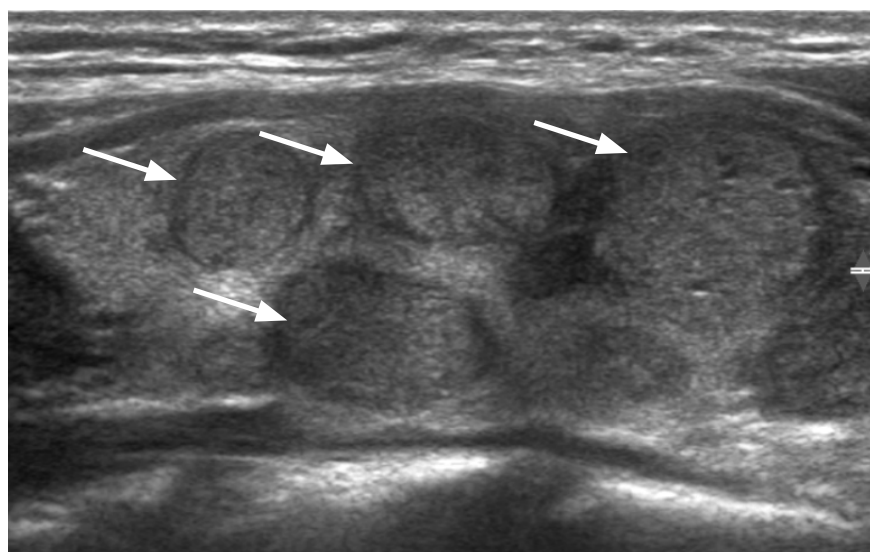

B

Fig. 5. Cribriform-morular variant of papillary thyroid carcinoma in a 16-year-old girl who tested positive for the APC gene.

A, B. Transverse (A) and longitudinal (B) ultrasonography shows multiple various-sized isoechoic and hypoechoic nodules (arrows) in both thyroid glands. C. Computed tomography shows mildly enhanced nodules. This tumor lacks malignant US features.

Table 2. Incidence and common ultrasonographic features of the PTC variants

\begin{tabular}{lll}
\hline \multicolumn{1}{c}{ Variant } & \multicolumn{1}{c}{ Incidence } & \multicolumn{1}{c}{ Common ultrasonographic feature } \\
\hline Tall cell variant & $4 \%-17 \%$ of PTCs & Typical malignant features ${ }^{\text {a) }}$, frequent nodal metastasis \\
Columnar cell variant & No report & Typical malignant features vs. circumscribed border \\
Hobnail variant & No report & Typical malignant features, frequent nodal metastasis \\
Solid variant & $3 \%$ of PTCs & Typical malignant features vs. circumscribed border \\
Diffuse sclerosing variant & $0.7 \%-6.6 \%$ of PTCs & IIl-defined mass, scattered microcalcifications, nodal metastasis \\
Follicular variant (encapsulated) & $10 \%-20 \%$ of all thyroid cancers & Solid hypoechoic or isoechoic nodule \\
Cribriform-morular variant & $1 \%$ of FAP patients & Solid oval to round nodule without calcification \\
Warthin-like variant & No report & Benign-looking nodule, heterogeneous parenchyma \\
\hline
\end{tabular}

PTC, papillary thyroid carcinoma; FAP, familial adenomatous polyposis.

${ }^{a}$ Typical malignant features include a solid hypoechoic nodule with microcalcification, a spiculated/microlobulated margin, or nonparallel orientation.

lower rate of BRAF mutations than does classic PTC (65\% vs. $84 \%$ ).

WV PTC has a favorable prognosis but can be misdiagnosed as a probably benign nodule or focal thyroiditis on US. All cases are associated with heterogeneous parenchyma in the background [52]. Table 2 is summerized in the incidence and common US features of PTC variants.

\section{Conclusion}

The US features at the time of diagnosis are helpful in predicting the biological behavior of PTC. With active surveillance replacing immediate biopsy or surgery for indolent, small PTCs, an understanding of the US characteristics of the variants of PTC will 
facilitate the individualized management of patients with PTC.

ORCID: Jung Hee Shin: http://orcid.org/0000-0001-6435-7357

\section{Conflict of Interest}

No potential conflict of interest relevant to this article was reported.

\section{References}

1. Ito $Y$, Kudo T, Kihara M, Takamura Y, Kobayashi K, Miya A, et al. Improvement of lymph node recurrence rate, but not distant recurrence and carcinoma death rates, in patients with papillary thyroid carcinoma after disease-free survival for 5 years. Endocr $\mathrm{J}$ 2012;59:895-901.

2. Nixon IJ, Ganly I, Patel SG, Palmer FL, Whitcher MM, Ghossein R, et al. Changing trends in well differentiated thyroid carcinoma over eight decades. Int I Surg 2012;10:618-623.

3. Nikiforov YE, Ohori NP. Papillary carcinoma. In: Nikiforov YE, Biddinger PW, Thompson LD, eds. Diagnostic pathology and molecular genetics of the thyroid. 2nd ed. Philadelphia, PA: Lippincott Williams and Wilkins, 2012;183-246.

4. Haugen BR, Alexander EK, Bible KC, Doherty GM, Mandel SJ, Nikiforov YE, et al. 2015 American Thyroid Association management guidelines for adult patients with thyroid nodules and differentiated thyroid cancer: The American Thyroid Association Guidelines Task Force on Thyroid Nodules and Differentiated Thyroid Cancer. Thyroid 2016;26:1-133.

5. Na DG, Kim JH, Kim DS, Kim SJ. Thyroid nodules with minimal cystic changes have a low risk of malignancy. Ultrasonography 2016;35:153-158.

6. Russ G. Risk stratification of thyroid nodules on ultrasonography with the French TI-RADS: description and reflections. Ultrasonography 2016;35:25-38.

7. Hahn SY, Shin JH, Oh YL, Son YI. Discrepancies between the ultrasonographic and gross pathological size of papillary thyroid carcinomas. Ultrasonography 2016;35:220-225.

8. Ghossein R, Livolsi VA. Papillary thyroid carcinoma tall cell variant. Thyroid 2008;18:1179-1181.

9. Ghossein RA, Leboeuf R, Patel KN, Rivera M, Katabi N, Carlson $D L$, et al. Tall cell variant of papillary thyroid carcinoma without extrathyroid extension: biologic behavior and clinical implications. Thyroid 2007;17:655-661.

10. Chan JK. Tumors of the thyroid and parathyroid glands. Part A. The thyroid gland. In: Fletcher $C D$, ed. Diagnostic histopathology of tumors. 2nd ed. London: Churchill-Livingstone, 2000;959-1038.

11. Bernstein J, Virk RK, Hui P, Prasad A, Westra WH, Tallini G, et al. Tall cell variant of papillary thyroid microcarcinoma: clinicopathologic features with BRAF(V600E) mutational analysis. Thyroid 2013;23:1525-1531.
12. Choi YJ, Shin JH, Kim JH, Jung SL, Son EJ, Oh YL. Tall cell variant of papillary thyroid carcinoma: sonographic and clinical findings. J Ultrasound Med 2011;30:853-858.

13. Evans HL. Columnar-cell carcinoma of the thyroid: a report of two cases of an aggressive variant of thyroid carcinoma. Am J Clin Pathol 1986;85:77-80.

14. Evans HL. Encapsulated columnar-cell neoplasms of the thyroid: a report of four cases suggesting a favorable prognosis. Am I Surg Pathol 1996;20:1205-1211.

15. Chen JH, Faquin WC, Lloyd RV, Nose V. Clinicopathological and molecular characterization of nine cases of columnar cell variant of papillary thyroid carcinoma. Mod Pathol 2011;24:739-749.

16. Albores-Saavedra J. Papillary thyroid carcinoma with prominent hobnail features: a new aggressive variant of moderately differentiated papillary carcinoma: a clinicopathologic, immunohistochemical, and molecular study of 8 cases. Am I Surg Pathol 2010;34:913.

17. Asioli S, Erickson LA, Sebo TJ, Zhang J, Jin L, Thompson GB, et al. Papillary thyroid carcinoma with prominent hobnail features: a new aggressive variant of moderately differentiated papillary carcinoma: a clinicopathologic, immunohistochemical, and molecular study of eight cases. Am J Surg Pathol 2010;34:44-52.

18. Lee YS, Kim Y, Jeon S, Bae JS, Jung SL, Jung CK. Cytologic, clinicopathologic, and molecular features of papillary thyroid carcinoma with prominent hobnail features: 10 case reports and systematic literature review. Int J Clin Exp Pathol 2015;8:79887997.

19. Carcangiu ML, Zampi G, Pupi A, Castagnoli A, Rosai J. Papillary carcinoma of the thyroid: a clinicopathologic study of 241 cases treated at the University of Florence, Italy. Cancer 1985;55:805828.

20. Nikiforov YE, Erickson LA, Nikiforova MN, Caudill CM, Lloyd RV. Solid variant of papillary thyroid carcinoma: incidence, clinicalpathologic characteristics, molecular analysis, and biologic behavior. Am J Surg Pathol 2001;25:1478-1484.

21. Nikiforov YE. Radiation-induced thyroid cancer: what we have learned from chernobyl. Endocr Pathol 2006;17:307-317.

22. Chang H, Kim SM, Chun KW, Kim BW, Lee YS, Chang HS, et al. Clinicopathologic features of solid variant papillary thyroid cancer. ANZ J Surg 2014;84:380-382.

23. Shin JH, Baek JH, Chung J, Ha EJ, Kim JH, Lee YH, et al. Ultrasonography diagnosis and imaging-based management of thyroid nodules: revised Korean Society of Thyroid Radiology consensus statement and recommendations. Korean J Radiol 2016;17:370-395.

24. Ha EJ, Moon WJ, Na DG, Lee YH, Choi N, Kim SJ, et al. A multicenter prospective validation study for the Korean thyroid imaging reporting and data system in patients with thyroid nodules. Korean J Radiol 2016;17:811-821.

25. Giorgadze TA, Scognamiglio T, Yang GC. Fine-needle aspiration 
cytology of the solid variant of papillary thyroid carcinoma: a study of 13 cases with clinical, histologic, and ultrasound correlations. Cancer Cytopathol 2015;123:71-81.

26. Vickery AL Jr, Carcangiu ML, Johannessen JV, Sobrinho-Simoes M. Papillary carcinoma. Semin Diagn Pathol 1985;2:90-100.

27. Hedinger C, Williams ED, Sobin LH. The WHO histological classification of thyroid tumors: a commentary on the second edition. Cancer 1989;63:908-911.

28. Carcangiu ML, Bianchi S. Diffuse sclerosing variant of papillary thyroid carcinoma: clinicopathologic study of 15 cases. Am J Surg Pathol 1989;13:1041-1049.

29. Soares J, Limbert E, Sobrinho-Simoes M. Diffuse sclerosing variant of papillary thyroid carcinoma: a clinicopathologic study of 10 cases. Pathol Res Pract 1989;185:200-206.

30. Zimmerman D, Hay ID, Gough IR, Goellner JR, Ryan JJ, Grant CS, et al. Papillary thyroid carcinoma in children and adults: long-term follow-up of 1039 patients conservatively treated at one institution during three decades. Surgery 1988;104:1157-1166.

31. Fujimoto Y, Obara T, Ito Y, Kodama T, Aiba M, Yamaguchi K. Diffuse sclerosing variant of papillary carcinoma of the thyroid: clinical importance, surgical treatment, and follow-up study. Cancer 1990;66:2306-2312.

32. Lam AK, Lo CY. Diffuse sclerosing variant of papillary carcinoma of the thyroid: a 35-year comparative study at a single institution. Ann Surg Oncol 2006;13:176-181.

33. Malandrino P, Russo M, Regalbuto C, Pellegriti G, Moleti M, Caff A, et al. Outcome of the diffuse sclerosing variant of papillary rhyroid cancer: a meta-analysis. Thyroid 2016;26:1285-1292.

34. Chereau N, Giudicelli X, Pattou F, Lifante JC, Triponez F, Mirallie E, et al. Diffuse sclerosing variant of papillary thyroid carcinoma is associated with aggressive histopathological features and a poor outcome: results of a large multicentric study. I Clin Endocrinol Metab 2016;101:4603-4610.

35. Joung JY, Kim TH, Jeong DJ, Park SM, Cho YY, Jang HW, et al. Diffuse sclerosing variant of papillary thyroid carcinoma: major genetic alterations and prognostic implications. Histopathology 2016;69:45-53.

36. Lee JY, Shin JH, Han BK, Ko EY, Kang SS, Kim JY, et al. Diffuse sclerosing variant of papillary carcinoma of the thyroid: imaging and cytologic findings. Thyroid 2007;17:567-573.

37. Tielens ET, Sherman SI, Hruban RH, Ladenson PW. Follicular variant of papillary thyroid carcinoma: a clinicopathologic study. Cancer 1994;73:424-431.

38. Rosai J, Zampi G, Carcangiu ML. Papillary carcinoma of the thyroid: a discussion of its several morphologic expressions, with particular emphasis on the follicular variant. Am J Surg Pathol 1983;7:809817.

39. Rivera M, Ricarte-Filho J, Knauf J, Shaha A, Tuttle M, Fagin JA, et al. Molecular genotyping of papillary thyroid carcinoma follicular variant according to its histological subtypes (encapsulated vs infiltrative) reveals distinct BRAF and RAS mutation patterns. Mod Pathol 2010;23:1191-1200.

40. Rhee SJ, Hahn SY, Ko ES, Ryu JW, Ko EY, Shin JH. Follicular variant of papillary thyroid carcinoma: distinct biologic behavior based on ultrasonographic features. Thyroid 2014;24:683-688.

41. Choi JW, Kim TH, Roh HG, Moon WJ, Lee SH, Hwang TS, et al. Radiologic and pathologic findings of a follicular variant of papillary thyroid cancer with extensive stromal fat: a case report. Korean J Radiol 2015;16:1349-1352.

42. Nikiforov YE, Seethala RR, Tallini G, Baloch ZW, Basolo F, Thompson LD, et al. Nomenclature revision for encapsulated follicular variant of papillary thyroid carcinoma: a paradigm shift to reduce overtreatment of indolent tumors. JAMA Oncol 2016;2:1023-1029.

43. Nikiforov YE. Ramifications of new terminology for encapsulated follicular variant of papillary thyroid Ccarcinoma: reply. JAMA Oncol 2016;2:1098-1099.

44. Hahn SY, Shin JH, Lim HK, Jung SL, Oh YL, Choi IH, et al. Preoperative differentiation between noninvasive follicular thyroid neoplasm with papillary-like nuclear features (NIFTP) and nonNIFTP. Clin Endocrinol (Oxf) 2017;86:444-450.

45. Yoon JH, Kwon HJ, Kim EK, Moon HJ, Kwak JY. The follicular variant of papillary thyroid carcinoma: characteristics of preoperative ultrasonography and cytology. Ultrasonography 2016;35:47-54.

46. Cetta F, Pelizzo MR, Curia MC, Barbarisi A. Genetics and clinicopathological findings in thyroid carcinomas associated with familial adenomatous polyposis. Am J Pathol 1999;155:7-9.

47. Lee S, Hong SW, Shin SJ, Kim YM, Rhee Y, Jeon BI, et al. Papillary thyroid carcinoma associated with familial adenomatous polyposis: molecular analysis of pathogenesis in a family and review of the literature. Endocr J 2004;51:317-323.

48. Chong Y, Shin JH, Oh YL, Han BK, Ko EY. Cribriform-morular variant of papillary thyroid carcinoma: ultrasonographic and clinical characteristics. Thyroid 2013;23:45-49.

49. Pradhan D, Sharma A, Mohanty SK. Cribriform-morular variant of papillary thyroid carcinoma. Pathol Res Pract 2015;211:712-716.

50. Apel RL, Asa SL, LiVolsi VA. Papillary Hurthle cell carcinoma with lymphocytic stroma: "Warthin-like tumor" of the thyroid. Am J Surg Pathol 1995;19:810-814.

51. Yeo MK, Bae JS, Lee S, Kim MH, Lim DJ, Lee YS, et al. The Warthinlike variant of papillary thyroid carcinoma: a comparison with classic type in the patients with coexisting Hashimoto's thyroiditis. Int J Endocrinol 2015;2015:456027.

52. Kim GR, Shin JH, Hahn SY, Ko EY, Oh YL. Ultrasonographic features and clinical characteristics of Warthin-like variant of papillary thyroid carcinoma. Endocr J 2016;63:329-335. 